\title{
Regorafenib for Metastatic Colorectal Cancer: An Analysis of a Registry-Based Cohort of 555 Patients
}

\begin{abstract}
Alena Novakova-Jiresova (D) Katerina Kopeckova ${ }^{2}$ Ludmila Boublikova' Renata Chloupkova ${ }^{3}$

Bohuslav Melichar ${ }^{4}$

Lubos Petruzelka ${ }^{5}$

Jindrich Finek ${ }^{6}$

Ondrej Fiala ${ }^{6,7}$

Peter Grell ${ }^{8}$

Stanislav Batko ${ }^{2}$

Zdenek Linke ${ }^{2}$

Igor Kiss ${ }^{8}$

Jana Prausova ${ }^{2}$

Tomas Buchler (D)

'Department of Oncology, First Faculty of Medicine and Thomayer Hospital, Charles University, Prague, Czech Republic;

${ }^{2}$ Department of Oncology, University Hospital in Motol, Charles University, Prague, Czech Republic; Institute of Biostatistics and Analysis, Faculty of Medicine, Masaryk University, Brno, Czech Republic; ${ }^{4}$ Department of Oncology, Palacky University Medical and Teaching Hospital, Olomouc, Czech Republic; ${ }^{5}$ Department of Oncology, General Faculty Hospital, Charles University, Prague, Czech Republic; ' ${ }^{6}$ Department of Oncology and Radiotherapy, Medical School and University Hospital in Pilsen, Charles University, Pilsen, Czech Republic; ${ }^{7}$ Biomedical Center, Faculty of Medicine in Pilsen, Charles University, Pilsen, Czech Republic; ${ }^{8}$ Department of Comprehensive Cancer Care, Masaryk Memorial Cancer Institute, Brno, Czech Republic
\end{abstract}

Correspondence: Tomas Buchler Department of Oncology, First Faculty of Medicine and Thomayer Hospital, Charles University, Videnska 800, Prague I40 59, Czech Republic

Tel +420-26I-082-637

$\mathrm{Fax}+420-26 \mathrm{I}-082-522$

Email tomas.buchler@ftn.cz
This article was published in the following Dove Press journal: Cancer Management and Research
Purpose: Regorafenib is an oral multikinase inhibitor approved for the therapy of previously treated metastatic colorectal carcinoma (mCRC). The aim of the present study was to analyze the outcomes of treatment with regorafenib in real-world clinical practice based on data from a national registry.

Methods: The CORECT registry, the Czech non-interventional database of patients with mCRC treated with targeted agents, searched for patients with metastatic CRC treated with regorafenib. In total, 555 evaluable patients were identified.

Results: The median age at diagnosis was 61.7 years. All patients had disease progression on or after previous systemic treatment. Most patients were treated with an initial dose of 160 $\mathrm{mg}$ daily $(\mathrm{n}=463 ; 83.6 \%)$. The median duration of treatment was 2.7 months (range 0.0 23.4 months). By the data cut-off date, 472 patients ( $85 \%$ ) had completed treatment with regorafenib and were evaluable for treatment response evaluation. Partial response was reported in 13 patients $(2.8 \%)$ and disease stabilization in 130 patients $(27.5 \%)$. Median progression-free survival (PFS) and overall survival (OS) were 3.5 months (95\% confidence interval [CI] 3.2-3.7 months) and 9.3 months (95\% CI 8.3-10.3 months), respectively. The 6-month OS rate was $67.7 \%$ (95\% CI 63.4-72.1\%). Multivariable analysis showed that female gender, longer interval from diagnosis of metastatic disease, M0 stage at diagnosis, and Eastern Cooperative Oncology Group performance status (ECOG PS) 0 were associated with longer PFS, while higher body-mass index (BMI), longer interval from diagnosis of metastatic disease, and ECOG PS of 0 were associated with longer OS.

Conclusion: OS of patients treated with regorafenib in the real-world clinical practice in this cohort exceeded that reported in randomized trials. Regorafenib is a safe and active treatment option for a subgroup of patients with mCRC who are progressing after other systemic therapies and maintain good performance status.

Keywords: colorectal cancer, regorafenib, registry, survival, outcome analysis

\section{Introduction}

With continuously rising incidence and mortality, colorectal cancer (CRC) has become the second most common cancer in the world and the third leading cause of cancer deaths in $2018 .^{1}$ The 5-year relative survival ranges from over $90 \%$ in patients with stage I disease to around $10 \%$ in patients with stage IV disease. ${ }^{2}$ However, with the introduction of targeted therapy over the past two decades, the life expectancy of patients with metastatic CRC (mCRC) has improved significantly from 12 to $30-40$ months in various studies.

Regorafenib is an oral multikinase inhibitor blocking activity of angiogenic, stromal and oncogenic protein kinases. ${ }^{3,5}$ Regorafenib has been approved in heavily 
pre-treated mCRC patients based on the results of a randomized double-blind placebo-controlled Phase III trial CORRECT (NCT01103323) that showed an OS benefit of regorafenib monotherapy over the best supportive care alone. $^{6}$ The previous treatment usually included chemotherapy regimens with fluoropyrimidine, oxaliplatin, irinotecan, combined with targeted antiangiogenic (antiVEGF) agents and, in wild-type RAS tumors, anti-EGFR therapy. ${ }^{6}$

The present study is based on a substantial expansion of the initial cohort of 148 regorafenib-treated patients from the Czech national registry. ${ }^{7}$ The objective of the study was to analyze treatment outcomes and associated prognostic factors in mCRC patients treated with regorafenib.

\section{Materials and Methods}

\section{Patients, Data Source, and Inclusion Criteria}

The national CORECT registry was used as a data source for the present analysis. The CORECT registry was a postmarketing database gathering anonymized data of CRC patients treated with targeted agents in the Czech Republic containing data on baseline characteristics, course of treatment, and outcomes.

The data entries were updated twice a year. The therapy with targeted agents in the Czech Republic outside of clinical trials is reimbursed only in comprehensive cancer centers, and the registry has been estimated to provide data on approximately $95 \%$ of all patients treated with targeted therapy for $\mathrm{mCRC}$ in these centers. ${ }^{8}$ There are 17 comprehensive cancer centers and all have contributed to the database. The contribution to the patient-based database was mandatory for regorafenib reimbursed by public health insurance. $^{7}$ There was no external monitoring of the data. The cohort for analysis included all patients with colorectal adenocarcinoma and valid data in the registry (including baseline patient characteristics, treatment, and follow-up data) who received regorafenib from 2011 to 2017. The data cut-off was October 2, 2017.

\section{Treatment}

Regorafenib (Stivarga, Bayer Pharma AG, Berlin, Germany) was administered according to the registration label to patients with $\mathrm{mCRC}$ previously treated with fluoropyrimidine, oxaliplatin, irinotecan, anti-VEGF therapy, and, in wild-type RAS tumors, also anti-EGFR therapy. The recommended initial dose was $160 \mathrm{mg}$ given as four
$40 \mathrm{mg}$ tablets orally daily for the first 21 days of a 28-day cycle. The treatment continued until disease progression or unacceptable toxicity. Dose reductions were at the discretion of the treating physician. The treatment response was evaluated by computed tomography (CT) according to the RECIST 1.1 criteria every 3 months. ${ }^{9}$

\section{Statistical Analysis}

Progression-free survival (PFS) was defined as the time from the regorafenib treatment initiation to the date of the first documented progression or death due to any cause. Overall survival (OS) was defined as the time from regorafenib treatment initiation to the date of death due to any cause. Response rates were calculated for patients with terminated treatment.

Descriptive statistics and frequency tables were used to characterize the sample data set. PFS and OS were estimated using Kaplan-Meier method and all point estimates include 95\% confidence intervals (95\% CI). Multivariable Cox proportional hazards model was used to evaluate independent effects of potential prognostic factors on the PFS and OS. Statistical significance of hazard ratios was assessed by Wald test. All statistical tests were performed at a significance level of $\alpha=0.05$. Power analysis was not performed - this analysis is a retrospective evaluation of the registry data and all results must be interpreted with respect to the confidence intervals.

\section{Results}

\section{Patient Characteristics}

In total, 555 patients treated with regorafenib between 2011 and 2017 were identified and included in the present analysis. The majority were male $(n=360,64.9 \%)$ and the median age at diagnosis was 61.7 years. The primary tumor localization was the left colon including rectum in 420 patients $(75.7 \%)$ and the right colon in 110 patients $(19.8 \%)$. Information on primary tumor localization was missing or there were multiple colon primary tumors in $4.5 \%$ of cases. Most patients $(n=343,61.8 \%)$ had had synchronous distant metastases at diagnosis, and the prevailing histology type was adenocarcinoma $(n=530$, $95.5 \%$ ). Mutations of RAS gene were detected in 258 cases $(46.5 \%)$. When initiating treatment with regorafenib, all patients were fully active or had only slightly reduced physical activity with ECOG performance status $0-1$, as required in the reimbursement conditions for the drug. Only $80(14.4 \%)$ patients received regorafenib within 18 
months of diagnosis of metastatic disease Baseline characteristics related to regorafenib treatment are summarized in Table 1.

Most patients were treated with an initial dose of 160 $m g$ daily $(n=463 ; 83.6 \%)$. The median treatment duration was 2.7 months (5-95th percentile range $0.4-8.6$ months).

Patients treated with the full initial dose of regorafenib were more likely to have liver-only metastatic disease (17.9 vs $7.7 \%, p=0.03$ ) and body-mass index $>25 \mathrm{~kg} / \mathrm{m}^{2}$ (66.9 vs $45.8 \%, p=0.001$ ) compared to those with a reduced initial dose, respectively. There were no significant differences in other baseline parameters.

The median follow-up for surviving patients was 5.4 months (0.1-38.9). At the time of data cut-off, 472 $(85.0 \%)$ patients had discontinued regorafenib therapy and disease progression or death was recorded for 339 $(71.8 \%)$ patients.

\section{Outcomes}

The median PFS was 3.5 months (95\% CI 3.2-3.7 months). However, the result also reflects the recommended 3-month intervals for tumor assessment by imaging. The relative 3month and 6-month PFS rates were 56.4\% (95\% CI 52.0 $60.8 \%$ ) and $24.5 \%$ (95\% CI 20.5-28.5\%), respectively (Figure 1).

The median OS reached 9.3 (95\% CI 8.3-10.3) months, with 3-month and 6-months OS rates of $87.0 \%$ (95\% CI $84.0-90.0 \%)$ and $67.7 \%$ (95\% CI 63.4-72.1\%), respectively (Figure 1).

By the data cut-off date, 472 patients (85\%) have completed treatment with regorafenib and were evaluable for treatment response evaluation. The overall response rate (ORR) was $2.8 \%$ (13/472 patients), and the disease control rate was $30.3 \%$ (143/472 patients).

The main cause of treatment discontinuation in the whole cohort of 555 treated patients was radiological or clinical disease progression $(\mathrm{n}=389 ; 70.1 \%)$. Treatment was discontinued for adverse events related to regorafenib in 21 patients (3.9\%), and for other reasons including loss of follow-up and patient decision in 62 patients (11.1\%). At the data cut-off date, 83 patients $(15.0 \%)$ continued with regorafenib treatment.

\section{Prognostic Factors}

Multivariable analysis revealed that female gender, longer time from diagnosis of metastatic disease, M0 stage at diagnosis, and ECOG PS 0 were associated with longer PFS, while
Table I Baseline Patient Characteristics

\begin{tabular}{|c|c|c|}
\hline Parameter & Subgroup & Value \\
\hline Gender, $\mathrm{n}(\%)$ & $\begin{array}{l}\text { Women } \\
\text { Men }\end{array}$ & $\begin{array}{l}195(35.1) \\
360(64.9)\end{array}$ \\
\hline Age at diagnosis years & Median (range) & $61.7(24.1-81.3)$ \\
\hline Age at regorafenib initiation years & Median (range) & $64.9(26.3-83.7)$ \\
\hline Site of primary tumor, $\mathrm{n}(\%)$ & $\begin{array}{l}\text { Left colon or } \\
\text { rectum } \\
\text { Right colon or } \\
\text { transversum } \\
\text { Colon without } \\
\text { side specification }\end{array}$ & $\begin{array}{l}420(75.7) \\
110(19.8) \\
25(4.5)\end{array}$ \\
\hline Distant metastasis at diagnosis, $\mathrm{n}(\%)$ & $\begin{array}{l}\text { Absent (MO) } \\
\text { Present (MI) }\end{array}$ & $\begin{array}{l}212(38.2) \\
343(61.8)\end{array}$ \\
\hline Primary tumor histology, n (\%) & $\begin{array}{l}\text { Adenocarcinoma } \\
\text { Mucinous } \\
\text { adenocarcinoma } \\
\text { Signet ring cell } \\
\text { carcinoma } \\
\text { Other }\end{array}$ & $\begin{array}{l}530(95.5) \\
15(2.7) \\
4(0.7) \\
6(1.1)\end{array}$ \\
\hline RAS status, n (\%) & $\begin{array}{l}\text { Mutated } \\
\text { Wild type }^{\mathrm{a}} \\
\text { Not tested/not } \\
\text { known }\end{array}$ & $\begin{array}{l}258(46.5) \\
280(50.5) \\
17(3.1)\end{array}$ \\
\hline BRAF status, n (\%) & $\begin{array}{l}\text { Mutated } \\
\text { Wild type } \\
\text { Not tested/not } \\
\text { known }\end{array}$ & $\begin{array}{l}23(4.1) \\
132(23.8) \\
400(72.1)\end{array}$ \\
\hline Prior therapies ${ }^{\mathrm{b}}, \mathrm{n}(\%)$ & $\begin{array}{l}\text { Bevacizumab } \\
\text { Cetuximab } \\
\text { Panitumumab } \\
\text { Aflibercept } \\
\text { Trifluridine/ } \\
\text { tipiracil }\end{array}$ & $\begin{array}{l}495(89.2) \\
131(23.6) \\
154(27.7) \\
90(16.2) \\
10(1.8)\end{array}$ \\
\hline $\begin{array}{l}\text { Time from diagnosis of CRC to } \\
\text { regorafenib treatment initiation } \\
\text { (months) }\end{array}$ & Median (range) & $34.5(5.1-168.4)$ \\
\hline $\begin{array}{l}\text { BMI at regorafenib treatment } \\
\text { initiation }{ }^{\mathrm{c}}, \mathrm{n}(\%)\end{array}$ & $\begin{array}{l}\leq 25 \mathrm{~kg} / \mathrm{m}^{2} \\
>25 \mathrm{~kg} / \mathrm{m}^{2}\end{array}$ & $\begin{array}{l}179(35.6) \\
324(64.4)\end{array}$ \\
\hline $\begin{array}{l}\text { Site of metastases at regorafenib } \\
\text { treatment initiation }{ }^{\mathrm{d}}, \mathrm{n}(\%)\end{array}$ & $\begin{array}{l}\text { Liver only } \\
\text { Other organs } \pm \\
\text { liver }\end{array}$ & $\begin{array}{l}90(16.5) \\
454(83.5)\end{array}$ \\
\hline $\begin{array}{l}\text { ECOG PS at regorafenib treatment } \\
\text { initiation, } n(\%)\end{array}$ & $\begin{array}{l}\text { PS } 0 \\
\text { PS I }\end{array}$ & $\begin{array}{l}187(33.7) \\
368(66.3)\end{array}$ \\
\hline Line of regorafenib treatment, $n$ (\%) & $\begin{array}{l}\text { 2nd line } \\
\text { 3rd line } \\
\text { 4th line } \\
\geq 5 \text { th line }\end{array}$ & $\begin{array}{l}39(7.0) \\
333(60.0) \\
134(24.1) \\
49(8.8)\end{array}$ \\
\hline
\end{tabular}

(Continued) 
Table I (Continued).

\begin{tabular}{|l|l|l|}
\hline Parameter & Subgroup & Value \\
\hline Initial dose of regorafenib, $\mathrm{n}(\%)$ & $160 \mathrm{mg}$ & $463(83.6)$ \\
& $120 \mathrm{mg}$ & $52(9.4)$ \\
& $80 \mathrm{mg}$ & $26(4.7)$ \\
& Other or not & $14(2.5)$ \\
& specified & \\
\hline
\end{tabular}

Notes: Including 72 patients KRAS wild-type and NRAS unknown. ${ }^{\mathrm{b} O n e}$ patient could have more than one prior therapy. ${ }^{\mathrm{C}} \mathrm{BMI}$ at regorafenib treatment initiation is unknown in 52 patients. ${ }^{d}$ Site of metastases at regorafenib treatment initiation is unknown in II patients.

Abbreviations: BMI, body-mass index; ECOG PS, Eastern Cooperative Oncology Group performance status.

higher BMI, longer time from diagnosis of metastatic disease, and ECOG PS of 0 were associated with longer OS. Age, tumor sidedness, site of metastases at regorafenib therapy initiation, and RAS status were not associated with outcome of regorafenib therapy (Table 2).

For Multivariable Cox proportional hazards model, Schoenfeld residuals were used to check the proportional hazards assumption, while examining influential observations or outliers was performed by deviance residuals. Concordance (C-index) in case of progression-free survival model was 0.604 (95\% CI: 0.573-0.635), C-index for overall survival was 0.662 (95\% CI: 0.625-0.699).

\section{Toxicity}

An adverse event due to treatment was the reason for treatment discontinuation in $21(4.4 \%)$ patients. Grade 3 or higher adverse events related to treatment were recorded in 25 patients $(4.5 \%)$, including hand-foot syndrome/skin reaction in $5(0.9 \%)$ patients, fatigue in $4(0.7 \%)$ patients, diarrhoea in $5(0.9 \%)$ patients, hypertension in $2(0.4 \%)$ patients, and other in $18(3.2 \%)$ patients.

\section{Discussion}

The present analysis of retrospective data of a national registry confirms the efficacy of regorafenib in a heavily pre-treated population of $\mathrm{mCRC}$ patients refractory to other systemic treatments. The observed survival in this expanded cohort of patients treated with regorafenib monotherapy was superior to OS outcomes in two prospective randomized placebo-controlled trials that led to registration of regorafenib ${ }^{6,10}$ as well as to the outcomes reported in subsequent single arm open label studies. ${ }^{11,12}$ The better outcomes in the present group of patients might be attributable to patient selection and more favorable baseline characteristics, in particular longer time from diagnosis to regorafenib initiation compared to the patients enrolled in the prospective trials. Nevertheless, a metaanalysis of retrospective studies has confirmed the efficacy results from randomized and other prospective studies, yielding a median OS of 7.3 months. ${ }^{13}$

The fact that only a minority of patients treated with third-line agents for $\mathrm{mCRC}$ including regorafenib and trifluridine-tipiracil respond to therapy has spurred the search for a clinically useful prognostic index to identify patients with higher likelihood of benefit. The ColonLife nomogram based on the presence of primary tumor, lactate dehydrogenase level, performance status, and peritoneal involvement, has been validated in this setting and there are other sets of
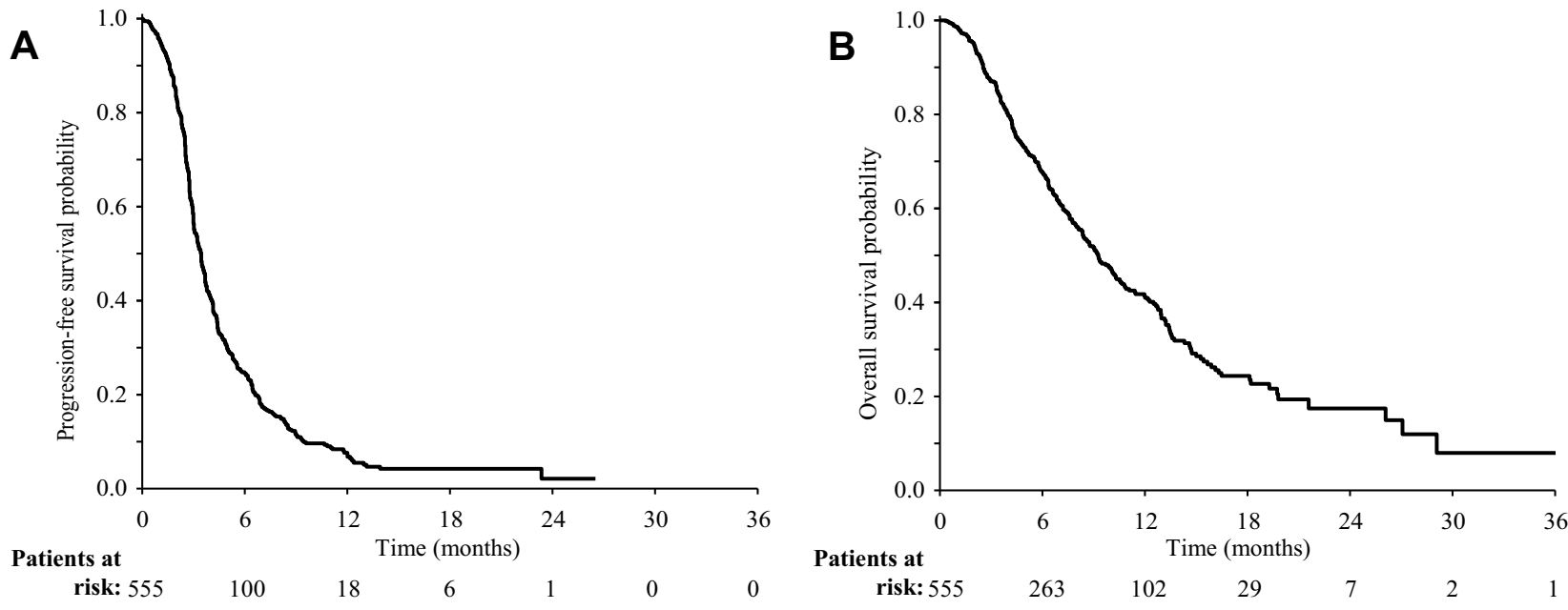

Figure I Progression-free (A) and overall (B) survival from regorafenib treatment initiation. 
Table 2 Progression-Free and Overall Survival Results - Multivariable Cox-Proportional Hazards Model

\begin{tabular}{|c|c|c|c|c|c|c|}
\hline \multirow[t]{3}{*}{ Variable } & \multirow[t]{3}{*}{ Category } & \multirow[t]{3}{*}{$\mathbf{n}$} & \multicolumn{2}{|c|}{ Progression-Free Survival } & \multicolumn{2}{|l|}{ Overall Survival } \\
\hline & & & \multirow{2}{*}{$\begin{array}{l}\text { HR } \\
(95 \% \mathrm{Cl})\end{array}$} & \multirow{2}{*}{$\begin{array}{l}\text { Wald Test } p \text { - } \\
\text { value }\end{array}$} & HR & \multirow{2}{*}{$\begin{array}{l}\text { Wald Test } \\
\text { p-value }\end{array}$} \\
\hline & & & & & $(95 \% \mathrm{Cl})$ & \\
\hline \multirow[t]{2}{*}{ Gender } & Female & 166 & 1.00 & - & 1.00 & - \\
\hline & Male & 310 & $1.26(1.01-1.57)$ & 0.042 & $1.15(0.87-1.5 \mathrm{I})$ & 0.331 \\
\hline \multirow[t]{2}{*}{ Age at treatment initiation } & $<60$ years & 135 & 1.00 & - & 1.00 & - \\
\hline & $\geq 60$ years & 341 & $0.96(0.77-1.21)$ & 0.736 & $0.98(0.74-1.30)$ & 0.907 \\
\hline \multirow[t]{2}{*}{ BMI at treatment initiation } & $\leq 25 \mathrm{~kg} / \mathrm{m}^{2}$ & 173 & 1.00 & - & 1.00 & - \\
\hline & $>25 \mathrm{~kg} / \mathrm{m}^{2}$ & 303 & $0.82(0.65-1.02)$ & 0.074 & $0.56(0.43-0.74)$ & $<0.001$ \\
\hline \multirow[t]{2}{*}{ Localization of primary tumour } & Left colon (including rectum) & 373 & 1.00 & - & 1.00 & - \\
\hline & Right colon & 103 & $1.21(0.93-1.56)$ & 0.151 & $1.12(0.82-1.53)$ & 0.483 \\
\hline \multirow{2}{*}{$\begin{array}{l}\text { Time from diagnosis to treatment } \\
\text { initiation }\end{array}$} & $<18$ months & 74 & 1.00 & - & 1.00 & - \\
\hline & $\geq 18$ months & 402 & $0.58(0.43-0.78)$ & $<0.001$ & $0.45(0.31-0.63)$ & $<0.001$ \\
\hline \multirow[t]{2}{*}{ Distant metastasis at diagnosis } & Absent (M0) & 178 & 1.00 & - & 1.00 & - \\
\hline & Present (MI) & 298 & $1.38(1.10-1.74)$ & 0.006 & $1.30(0.97-1.74)$ & 0.079 \\
\hline \multirow{2}{*}{$\begin{array}{l}\text { Site of metastases at treatment } \\
\text { initiation }\end{array}$} & Liver metastases only & 80 & 1.00 & - & 1.00 & - \\
\hline & $\begin{array}{l}\text { Liver and other organs/extrahepatic } \\
\text { metastases only }\end{array}$ & 396 & $0.91(0.68-1.20)$ & 0.495 & $1.03(0.72-1.48)$ & 0.858 \\
\hline \multirow[t]{2}{*}{ ECOG PS at treatment initiation } & PS 0 & 169 & 1.00 & - & 1.00 & - \\
\hline & PS I & 307 & $1.26(1.01-1.57)$ & 0.039 & $1.80(1.36-2.39)$ & $<0.001$ \\
\hline \multirow[t]{2}{*}{ RAS status } & Mutated & 231 & 1.00 & - & 1.00 & - \\
\hline & Wild type & 245 & $0.96(0.78-1.18)$ & 0.681 & $1.05(0.8 \mathrm{I}-1.37)$ & 0.704 \\
\hline
\end{tabular}

Abbreviations: BMI, body-mass index; ECOG PS, Eastern Cooperative Oncology Group performance status.

variables that may provide a tool for treatment individualization. ${ }^{11,14,15}$ In the REBECCA study based on real-life data inferior survival was associated with poor performance status and short time from initial diagnosis of metastases to the start of regorafenib, in agreement with the present data. The French group also reported reduced initial regorafenib dosage, $>3$ metastatic sites, presence of liver metastases, and KRAS mutations as adverse factors for survival. ${ }^{11}$ Grell et al ${ }^{15}$ have added inflammatory biomarkers including baseline white blood cell count and C-reactive protein concentration to increase the predictive strength of an index based on clinical parameters.

Interestingly, progressive sarcopenia has been associated with regorafenib treatment in a small study by Huemer et al. ${ }^{16}$ While requiring further validation and expansion this observation suggests that patients with sarcopenia should be considered for alternative therapies such as trifluridine-tipiracil or supportive care only. BMI $>25$ was associated with substantially better OS in the present cohort and there are data showing that low BMI is associated with sarcopenia. ${ }^{17,18}$
A hypothesis about different prognosis of CRC tumors associated with the distinct genetic profiles as determined by primary site (proximal vs distal colon and rectum) has been re-appearing in the literature since early the 1990s. ${ }^{19,23}$ Although this association was not confirmed in the present multivariable analysis, it is worth noting that gender, which has been shown to correlate with frequency of proximal versus distal CRC remained an independent indicator of the outcome in multivariable analysis of the present cohort. ${ }^{20,22}$ Conflicting accounts of gender impacting outcomes of CRC treatment can be encountered in the literature. Some studies failed to demonstrate the prognostic value of gender in CRC patients, ${ }^{24}$ while others report worse outcomes in females with right-sided tumors. ${ }^{22,25}$ Nevertheless, large meta-analyses have indicated inferior prognosis in males, ${ }^{23}$ possibly due to a complex association between impact of gender, age, BRAF mutational status, and primary tumor location on CRC prognosis. ${ }^{2,22,23,25,27}$ The inhibitory activity, documented in experimental studies, of regorafenib on mutated RAF proteins associated with poor-prognosis right-sided tumors could be an explanation of similar PFS in patients on 
regorafenib therapy, the observed regardless of the primary tumor site. ${ }^{3}$ No difference in OS between left and right has been demonstrated in the CORRELATE trial analyzing 474 patients, ${ }^{28}$ suggesting that regorafenib may counterbalance the negative prognostic impact that has been linked to rightsidedness of the primary tumor in mCRC. ${ }^{22}$

The weak points of the present study include possible selection bias inherent to the retrospective, registry-based design, and the absence of a control cohort. Toxicity was underreported in the registry. Because regorafenib is currently used in heavily pretreated patients with $\mathrm{mCRC}$, dose escalation strategy seems to be a rational approach improving safety compared to standard dosing without compromising treatment efficacy according to a recent meta-analysis. $^{29,30}$ This strategy has been adopted by many clinicians and the recently published data from the prospective CORRELATE study suggest that regorafenib is initiated in nearly half of patients at a reduced dose. The median OS in that study was 7.7 months. ${ }^{28}$ However, this approach was not commonly used in the present cohort due to reimbursement restrictions and valid comparison of outcomes was not possible. As many patients treated with regorafenib progress early, PFS results were influenced by the interval to first restaging CT scan which was 3 months in our study contrasting with 2 months in the CORRECT trial.

\section{Conclusion}

Outcomes of patients treated with regorafenib in the Czech real-world clinical database were superior to results reported in randomized trials, possibly due to the selection of patients with more favorable prognostic characteristics. Regorafenib is a safe and active treatment option for patients with $\mathrm{mCRC}$ who are progressing after other systemic therapies and maintaining good performance status.

\section{Ethics Statement}

The CORECT registry has been approved by the Multicentric Ethical Committee of the Brno University Hospital, Brno, Czech Republic as a noninterventional postregistration study. Summary analytical reports from the CORECT registry are publicly available at http://cor ect.registry.cz/index.php?pg=analyzy. Individual data are not publicly available.

\section{Acknowledgments}

This work was presented in part at the ESMO 2018 Congress in Munich, Germany, 19-23 October, 2018.
We would like to thank the following heads of the comprehensive cancer centers for the permission to use data of patients from their respective regional networks: Dr Martina Chodacka, Chomutov Hospital and Masaryk Hospital in Usti nad Labem; Dr Vaclav Janovsky, Ceske Budejovice Hospital; Professor Jiri Mayer, University Hospital, Brno; Dr Jakub Cvek, University Hospital, Ostrava; Professor Jiri Petera, University Hospital, Hradec Kralove; Dr Jana Katolicka, St Anna University Hospital, Brno; Professor Marek Svoboda, Masaryk Memorial Institute of Oncology, Brno; Dr Jiri Bartos, Regional Hospital, Liberec; Dr Martin Safanda, Na Homolce Hospital, Prague; Dr Miloslav Pala, Na Bulovce Hospital, Prague; Dr Renata Soumarova, University Hospital Kralovske Vinohrady, Prague; Dr Milan Kohoutek, T Bata Hospital, Zlin; Dr Lubomir Slavicek, Jihlava Hospital. We are also indebted to all physicians who provided data for the CORECT registry.

\section{Author Contributions}

All authors contributed to data analysis, drafting or revising the article, gave final approval of the version to be published, and agree to be accountable for all aspects of the work.

\section{Funding}

The Institute of Biostatistics and Analysis, Faculty of Medicine, Masaryk University, Brno received financial support for the CORECT registry from Bayer, Amgen Merck and Roche.

\section{Disclosure}

Renata Chloupkova reports The Institute of Biostatistics and Analysis, Faculty of Medicine, Masaryk University, Brno, received financial support for the CORECT registry from Bayer, Amgen Merck and Roche, during the conduct of the study. Katerina Kopeckova received grants and payment for lectures from Bayer. Tomas Buchler received grants, consulting fees and support for travel from Bayer. Bohuslav Melichar received consulting fees from Roche, Novartis, Astellas, Bristol-Myers Squibb, MSD, Merck, Pfizer, Janssen, support for travel from Roche, Novartis, Astellas, Bristol-Myers Squibb, provision of writing assistance from Roche, Bristol-Myers Squibb, payment for lectures from Roche, Novartis, Astellas, Bristol-Myers Squibb, MSD, Merck, Pfizer, Janssen, and personal fees and honoraria for speeches and advisory board service from Bayer and Sevier, outside the submitted work. 
Jindrich Finek reports being an advisor for and personal fees from Roche, Pierre fabre, MSD, Janssen, BMS, Merck, and Pfizer, during the conduct of the study. Ondrej Fiala received honoraria from Roche, Janssen, GSK and Pfizer for consultations and lectures unrelated to this project. Tomas Buchler reports grants and personal fees from Bayer, Roche, Novartis, and Bristol Myers Squibb, and personal fees from Amgen, Servier, and Ipsen, outside the submitted work. The other authors have declared no conflicts of interest in this work.

\section{References}

1. Bray F, Ferlay J, Soerjomataram I, Siegel RL, Torre LA, Jemal A. Global cancer statistics 2018: GLOBOCAN estimates of incidence and mortality worldwide for 36 cancers in 185 countries. CA Cancer J Clin. 2018;68(6):394-424. doi:10.3322/caac.21492

2. Brenner H, Kloor M, Pox CP. Colorectal cancer. Lancet. 2014;383 (9927):1490-1502. doi:10.1016/S0140-6736(13)61649-9

3. Wilhelm SM, Carter C, Tang L, et al. BAY 43-9006 exhibits broad spectrum oral antitumor activity and targets the RAF/MEK/ERK pathway and receptor tyrosine kinases involved in tumor progression and angiogenesis. Cancer Res. 2004;64(19):7099-7109. doi:10.1158/ 0008-5472.CAN-04-1443

4. Wilhelm SM, Dumas J, Adnane L, et al. Regorafenib (BAY 73-4506): a new oral multikinase inhibitor of angiogenic, stromal and oncogenic receptor tyrosine kinases with potent preclinical antitumor activity. Int $J$ Cancer. 2011;129(1):245-255. doi:10.1002/ijc.25864

5. Schmieder R, Hoffmann J, Becker M, et al. Regorafenib (BAY 73-4506): antitumor and antimetastatic activities in preclinical models of colorectal cancer. Int $J$ Cancer. 2014;135(6):1487-1496. doi:10.1002/ijc. 28669

6. Grothey A, Van Cutsem E, Sobrero A, et al. Regorafenib monotherapy for previously treated metastatic colorectal cancer (CORRECT): an international, multicentre, randomised, placebo-controlled, phase 3 trial. Lancet. 2013;381(9863):9863. doi:10.1016/S0140-6736(12) 61900-X

7. Kopeckova K, Buchler T, Bortlicek Z, et al. Regorafenib in the reallife clinical practice: data from the Czech registry. Target Oncol. 2017;12(1):89-95. doi:10.1007/s11523-016-0458-1

8. Buchler T, Chloupkova R, Poprach A, et al. Sequential therapy with bevacizumab and EGFR inhibitors for metastatic colorectal carcinoma: a national registry-based analysis. Cancer Manag Res. 2019;11:359-368. doi:10.2147/CMAR.S183093

9. Eisenhauer EA, Therasse P, Bogaerts J, et al. New response evaluation criteria in solid tumours: revised RECIST guideline (version 1.1). Eur J Cancer. 2009;45(2):228-247. doi:10.1016/j.ejca.2008.10.026

10. Li J, Qin S, Xu R, et al. Regorafenib plus best supportive care versus placebo plus best supportive care in Asian patients with previously treated metastatic colorectal cancer (CONCUR): a randomised, double-blind, placebo-controlled, phase 3 trial. Lancet Oncol. 2015;16 (6):619-629. doi:10.1016/S1470-2045(15)70156-7

11. Adenis A, de la Fouchardiere C, Paule B, et al. Survival, safety, and prognostic factors for outcome with Regorafenib in patients with metastatic colorectal cancer refractory to standard therapies: results from a multicenter study (REBECCA) nested within a compassionate use program. BMC Cancer. 2016;16(1):412. doi:10.1186/s12885-016-2440-9

12. Van Cutsem E, Martinelli E, Cascinu S, et al. Regorafenib for patients with metastatic colorectal cancer who progressed after standard therapy: results of the large, single-arm, open-label phase IIIb CONSIGN study. Oncologist. 2019;24(2):185-192. doi:10.1634/ theoncologist.2018-0072
13. Mercier J, Voutsadakis IA. A systematic review and meta-analysis of retrospective series of regorafenib for treatment of metastatic colorectal cancer. Anticancer Res. 2017;37(11):5925-5934. doi:10.21873/ anticanres. 12039

14. Pietrantonio F, Miceli R, Rimassa L, et al. Estimating 12-week death probability in patients with refractory metastatic colorectal cancer: the colon life nomogram. Ann Oncol. 2017;28(3):555-561. doi:10. 1093/annonc/mdw627

15. Grell P, Borilova S, Schwanzerova R, et al. Factors associated with effectiveness of trifluridine/tipiracil versus regorafenib in patients with pretreated metastatic colorectal cancer (mCRC). J Clin Oncol. 2020;38(4_suppl):137. doi:10.1200/JCO.2020.38.4_suppl.137

16. Huemer F, Schlintl V, Hecht S, et al. Regorafenib is associated with increased skeletal muscle loss compared to TAS-102 in metastatic colorectal cancer. Clin Colorectal Cancer. 2019;18(2):159-166.e3. doi:10.1016/j.clcc.2019.04.003

17. Sasaki S, Oki E, Saeki H, et al. Skeletal muscle loss during systemic chemotherapy for colorectal cancer indicates treatment response: a pooled analysis of a multicenter clinical trial (KSCC 1605-A). Int J Clin Oncol. 2019;24(10):1204-1213. doi:10.1007/s10147-019-01460-8

18. Barret M, Antoun S, Dalban C, et al. Sarcopenia is linked to treatment toxicity in patients with metastatic colorectal cancer. Nutr Cancer. 2014;66(4):583-589. doi:10.1080/01635581.2014.894103

19. Bufill JA. Colorectal cancer: evidence for distinct genetic categories based on proximal or distal tumor location. Ann Intern Med. 1990;113(10):779-788. doi:10.7326/0003-4819-113-10-779

20. Iacopetta B. Predictive values of sex and tumour site for survival benefit from 5FU in colorectal cancer. $\mathrm{Br} J$ Cancer. 2002;86 (9):1524-1526. doi:10.1038/sj.bjc.6600279

21. Yamauchi M, Morikawa T, Kuchiba A, et al. Assessment of colorectal cancer molecular features along bowel subsites challenges the conception of distinct dichotomy of proximal versus distal colorectum. Gut. 2012;61(6):847-854. doi:10.1136/gutjnl-2011-300865

22. Price TJ, Beeke C, Ullah S, et al. Does the primary site of colorectal cancer impact outcomes for patients with metastatic disease? Cancer. 2015;121(6):830-835. doi:10.1002/cncr.29129

23. Yang Y, Wang G, He J, et al. Gender differences in colorectal cancer survival: a meta-analysis. Int J Cancer. 2017;141(10):1942-1949. doi:10.1002/ijc.30827

24. Eker B, Ozaslan E, Karaca H, et al. Factors affecting prognosis in metastatic colorectal cancer patients. Asian Pac J Cancer Prev. 2015;16(7):3015-3021. doi:10.7314/apjcp.2015.16.7.3015

25. Kim S-E, Paik HY, Yoon H, Lee JE, Kim N, Sung M-K. Sex- and gender-specific disparities in colorectal cancer risk. World $J$ Gastroenterol. 2015;21(17):5167-5175. doi:10.3748/wjg.v21.i17.5167

26. Roth AD, Tejpar S, Delorenzi M, et al. Prognostic role of KRAS and BRAF in stage II and III resected colon cancer: results of the translational study on the PETACC-3, EORTC 40993, SAKK 60-00 trial. $J$ Clin Oncol. 2010;28(3):466-474. doi:10.1200/JCO.2009.23.3452

27. Lech G, Slotwinski R, Slodkowski M, Krasnodebski IW. Colorectal cancer tumour markers and biomarkers: recent therapeutic advances. World J Gastroenterol. 2016;22(5):1745-1755. doi:10.3748/wjg.v22. i5.1745

28. Ducreux M, Petersen LN, Ohler L, et al. Safety and effectiveness of regorafenib in patients with metastatic colorectal cancer in routine clinical practice in the prospective, observational CORRELATE study. Eur J Cancer. 2019;123:146-154. doi:10.1016/j.ejca.2019.09.015

29. Bekaii-Saab TS, Ou F-S, Ahn DH, et al. Regorafenib dose-optimisation in patients with refractory metastatic colorectal cancer (ReDOS): a randomised, multicentre, open-label, phase 2 study. Lancet Oncol. 2019;20(8):1070-1082. doi:10.1016/S1470-2045(19)30272-4

30. Fedyanin M, Polyanskaya E, Pokataev I, Tryakin A, Tjulandin S. Started dose of regorafenib and overall survival (OS) in patients (pts) with metastatic colorectal cancer (mCRC): a systematic review and meta-analysis. J Clin Oncol. 2020;38(4_suppl):131. doi:10.1200/ JCO.2020.38.4_suppl.131 


\section{Publish your work in this journal}

Cancer Management and Research is an international, peer-reviewed open access journal focusing on cancer research and the optimal use of preventative and integrated treatment interventions to achieve improved outcomes, enhanced survival and quality of life for the cancer patient.

The manuscript management system is completely online and includes a very quick and fair peer-review system, which is all easy to use. Visit http://www.dovepress.com/testimonials.php to read real quotes from published authors. 